\title{
Pemanfaatan Lahan Pasca Penambangan, Grasberg, Papua, Indonesia
}

\author{
Ghina Rasyida Yasri dan Erwin Sudarma \\ Departemen Arsitektur, Fakultas Teknik Sipil dan Perencanaan, Institut Teknologi Sepuluh Nopember (ITS) \\ e-mail: airwind@arch.its.ac.id
}

\begin{abstract}
Abstrak - Tidak dapat dipungkiri bahwa kegiatan penambangan di Indonesia memberikan banyak dampak yang positif maupun yang negatif pada lingkungan sekitarnya. Kerusakan lingkungan merupakan dampak negatif yang dapat terlihat secara fisik dan dirasakan secara non fisik. Hal seperti ini mengakibatkan lahan pasca penambangan menjadi tidak produktif lagi. Rehabilitasi lahan harus dilakukan agar lahan dapat dimanfaatkan lagi. Rehabilitasi merupakan salah satu solusi pemulihan lahan agar menjadi lebih bernilai tanpa harus dikembalikan pada bentuk awalnya. Lahan bekas Tambang Grasberg, Papua merupakan salah satu pertambangan di Indonesia yang harus di rehabilitasi dan dimanfaatkan untuk fasilitas lain yang lebih bermakna. Fasilitas edukasi salah satunya, pusat riset khusus pertambangan dengan pendekatan ekologis. Pusat riset ini sangat tepat karena konteks lokasi yang dapat dimanfaatkan sebagai sumber ilmu. Pendekatan ekologis bertujuan agar bangunan arsitektural tidak menambah kerusakan lingkungan sekitar, melainkan membantu memperbaiki lingkungan sekitar.
\end{abstract}

Kata Kunci-Redesain, Kebun Binatang, Biophilic.

\section{PENDAHULUAN}

$\mathrm{P}$ ERMASALAHAN lingkungan yang ada di sekitar pertambangan dewasa ini masih terbilang tinggi, dampak kegiatannya pada umumnya akan merubah bentang alam (rona lingkungan awal) dan peruntukan alam, berpotensi meningkatkan erosi dan sedimentasi, serta penurunan flora dan fauna. Pada skala besar dapat berdampak pada penumpukan limbah bahkan bisa terjadi penurunan kualitas air permukaan dan air tanah serta perubahan aspek sosial. Dengan demikian lahan menjadi tidak produktif dan ditinggalkan, tanpa ada pemanfaatan lain yang sebenarnya dapat menambang keuntungan bagi masyarakat sekitar bahkan negara.

Galian tambang Grasberg ini terletak di kota Tembagapura, Papua. Lokasi lahan ini berada di ketinggian 4.285 mdpl. Lahan yang dipilih terletak di daerah Pegunungan Jayawijaya. Lahan ini berada di area terpencil, namun sudah memiliki akses jalan untuk menuju lokasi. Di sekitar lahan terdapat perkantoran, pergudangan, dan area pengolahan hasil tambang.

"Pusat Riset Pertambangan Grasberg" adalah sebuah sarana edukasi dan riset khusus pertambangan. Selain itu objek ini juga dapat memfasilitsi kegiatan rehabilitasi pasca tambang. Sebuah sarana edukasi dan riset dilihat sangat tepat karena lingkungan sekitar tambang bisa menjadi sumber pembelajaran, pelatihan dan penelitian. Laboratorium yang ada dalam rancangan juga dapat bekerjasama dengan Freeport sebagai perusahaan pengelola tambang.

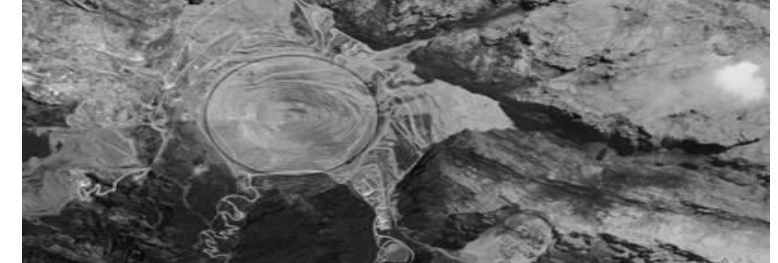

Gambar 1. Lokasi Tambang Grasberg.

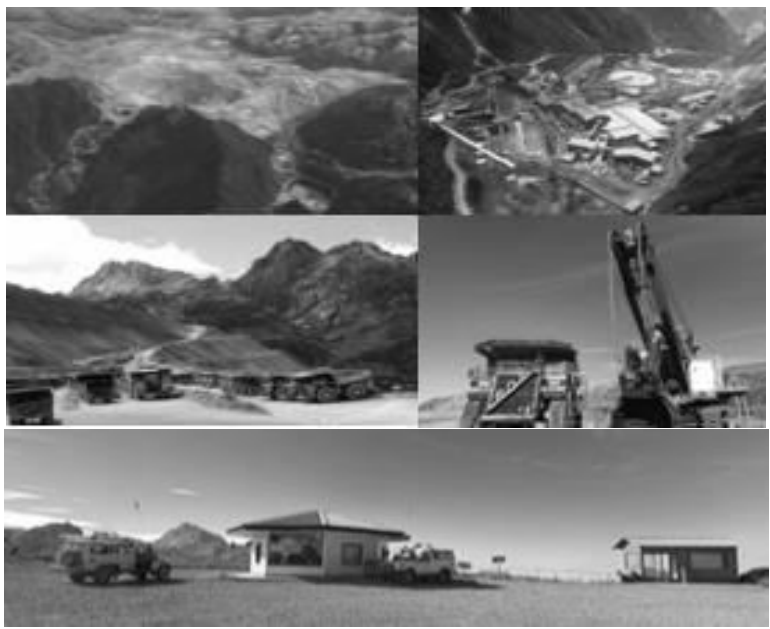

Gambar 2 . Kondisi Lingkungan Sekitar Tambang

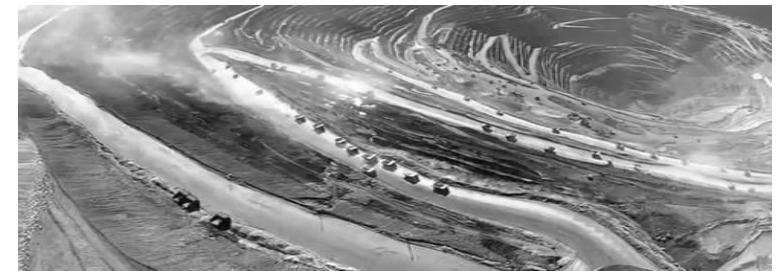

Gambar 3. Bentuk Kontur Pada Lahan.

\section{METODA PERANCANGAN}

Metode yang digunakan dalam proses desain ini adalah Rationalist Approaches. Metode ini merupakan salah satu klasifikasi metode desain menurut Kari Jormakka di dalam buku Basics Design Method. Metode Rationalist Approaches membutuhkan adanya pengetahuan dasar dari bidang lain di luar arsitektur. Pengetahuan dasar yang dimaksud harus rasional dan informasi yang spesifik (seperti lahan dan lingkungan sekitarnya) sehingga dapat mendukung perancangan. Salah satu metode yang termasuk dalam klasifikasi Rationalist Approaches adalah Performance Form. Salah satu cara untuk mengaplikasikan metode desain Performance Form maka dalam desain ini menggunakan pendekatan ekologis untuk penyelesaian desain secara fisik. 


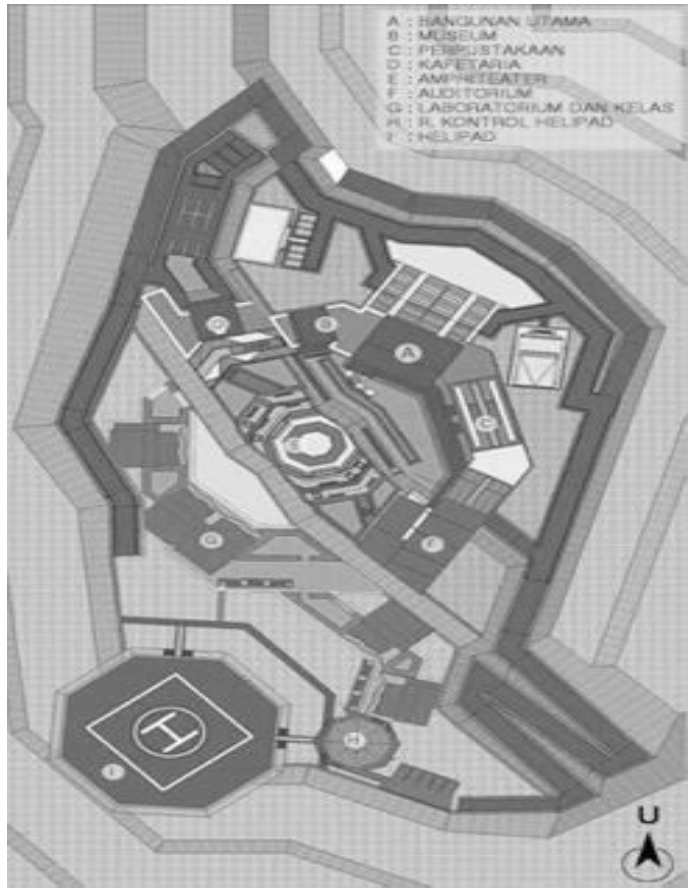

Gambar 4. Rencana Tapak

Sumber: Dokumentasi Pribadi
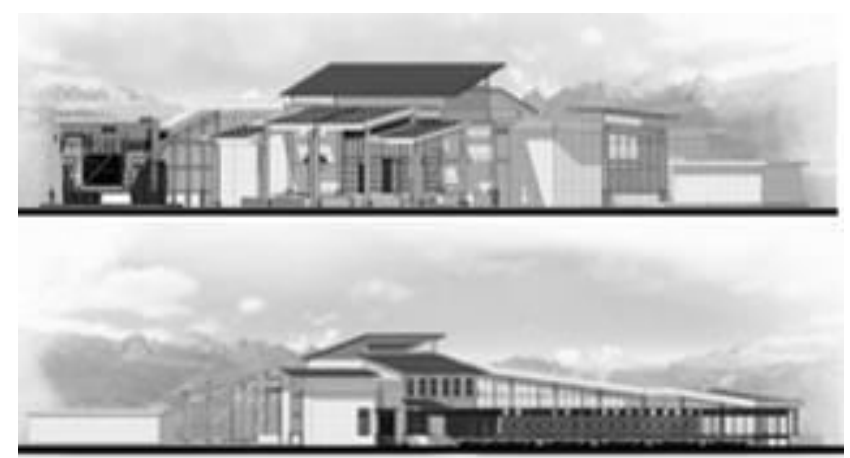

Gambar 5. Tampak Bangunan

Sumber: Dokumentasi Pribadi

Pendekatan arsitektur ekologis dalam desain ini bertujuan untuk mendesain sistem dalam maupun luar bangunan yang mampu membantu proses rehabilitasi lahan yang tidak produktif. Menurut Ken Yeang, konsep membangun yang utama dalam arsitektur ekologis adalah memperhtikan keseimbangan lingkungan alam dan buatan dengan unsur utama manusia, bangunan, dan lingkungan serta mengurangi dampak destruktif terhadap lingkungan.

Arsitektur ekologis memiliki empat dasaran utama unutk menjadikannya arsitektur yang sadar lingkungan, yaitu :

\section{A. Holistik}

Keselarasan dalam eko-arsitektur ini mecakup antara manusia dan lingkungan alamnya. Eko-arsitektur mengadung juga dimensi lain seperti waktu, lingkungan alam, kultur dan sosial, ruang, serta teknik bangunan. Hal ini menunjukkan bahwa eko-arsitektur bersifat lebih kompleks, padat, dan vital dibandingkan dengan arsitektur pada umumnya.

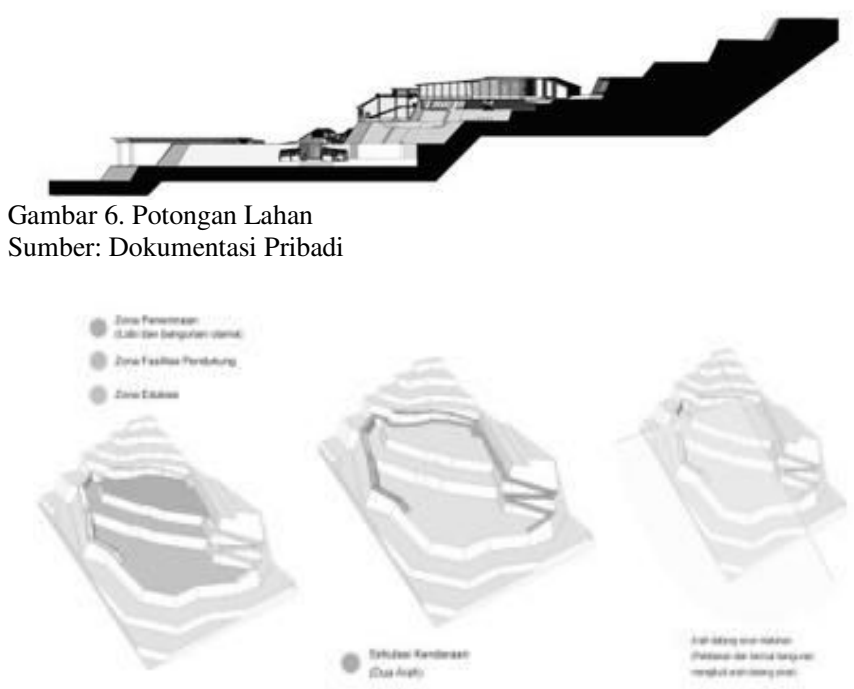

Gambar 7. Konsep Ide

Sumber: Dokumentasi Pribadi

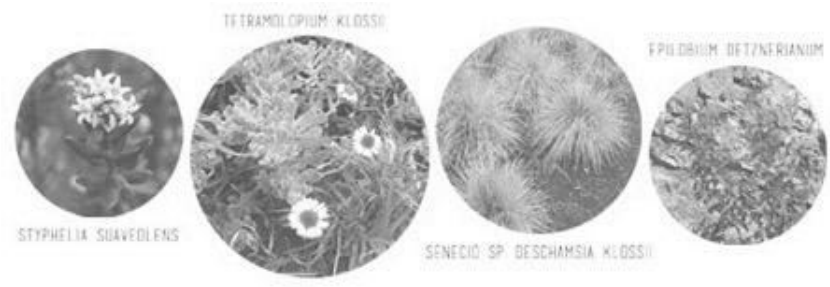

Gambar 8. Jenis - Jenis Tanaman yang Dapat Tumbuh.

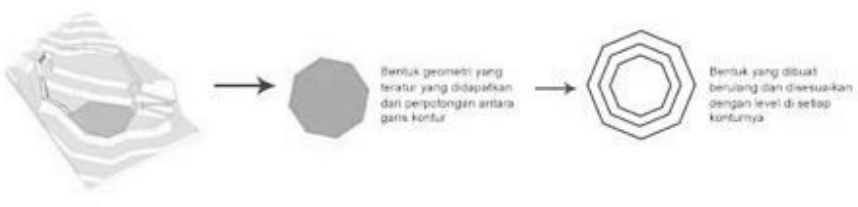

Gambar 9. Transformasi Bentuk Sumber: Dokumentasi Pribadi

\section{B. Hemat Energi}

Energi sangat dibutuhkan di dalam bangunan untuk meningkatkan kenyamanan penggunanya. Untuk menghasilkan suatu energi akan dibutuhkan bahan bakar, dalam arsitektur ekologis ini penggunaan bahan bakar sangat diutamakan pada bahan-bahan yang bisa diperbaharui dengan mudah ataupun memanfaatkan dari hasil alam terdekat yang dapat mengurangi produksi karbon di atmosfer.

\section{Material Ramah Lingkungan}

Beberapa prinsip material ramah lingkungan yang diterapkan dalam bangunan :

- Menggunakan bahan baku, energi, dan air seminimal mungkin.

- Menghindari penggunaan bahan bangunan dengan bahan yang berbahaya (logam berat, chlor).

- Bahan yang digunakan kuat dan tahan lama.

- Bahan bangunan atau bagian bangunan harus mudah diperbaiki dan diganti. 

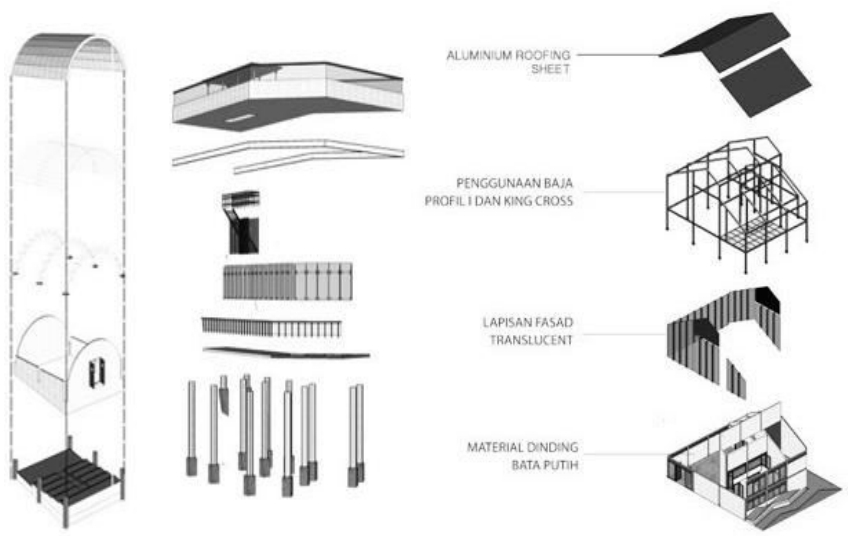

Gambar 10. Aksonometri Struktur

(R. Kelas Pelatihan, Area Komunal, dan Laboratorium)

Sumber: Dokumentasi Pribadi

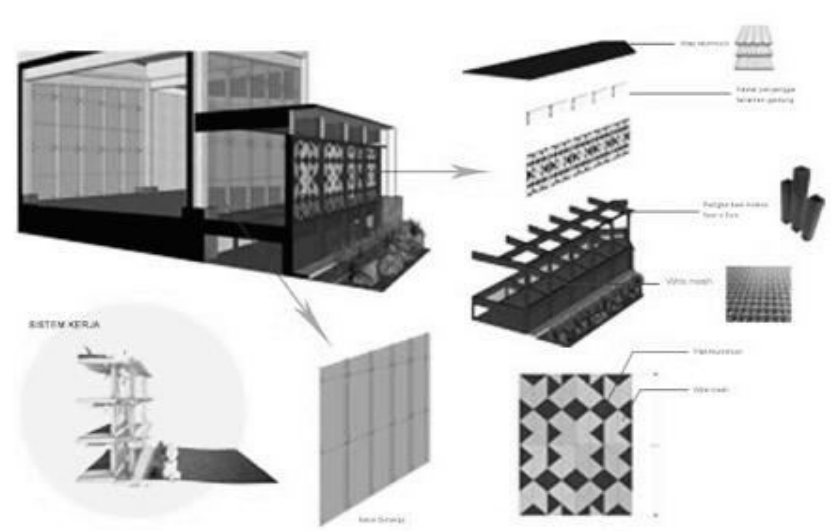

Gambar 11. Double Skin Facade Sumber: Dokumentasi Pribadi

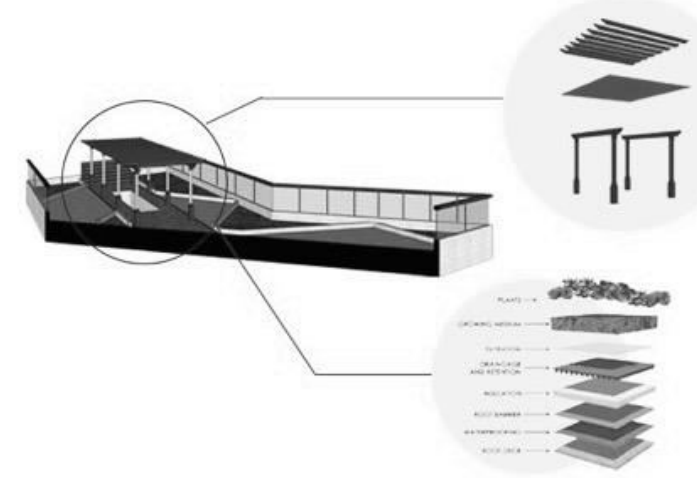

Gambar 12. Detail Green Roof

Sumber: Dokumentasi Pribadi

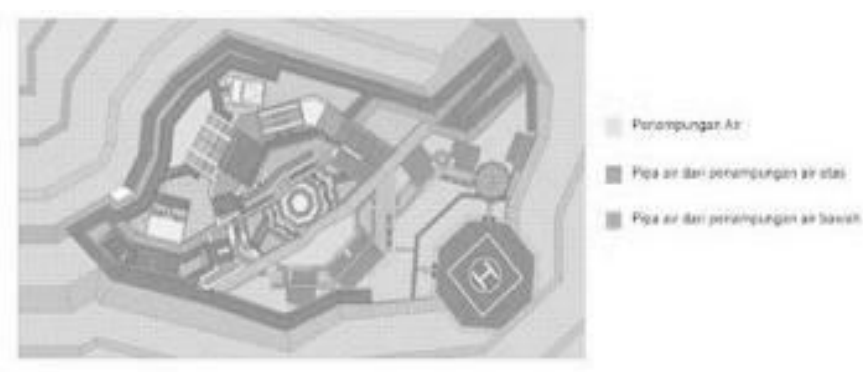

Gambar 13. Skema Utilitas Air Sumber: Dokumentasi Pribadi

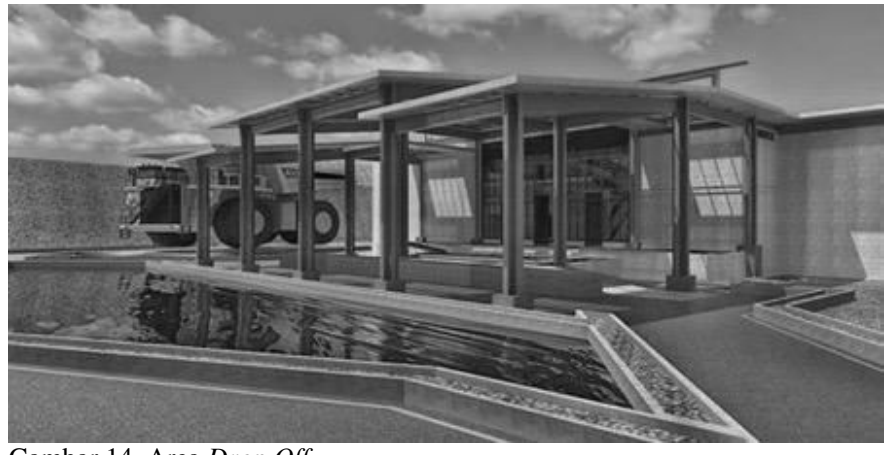

Gambar 14. Area Drop Off

Sumber: Dokumentasi Pribadi

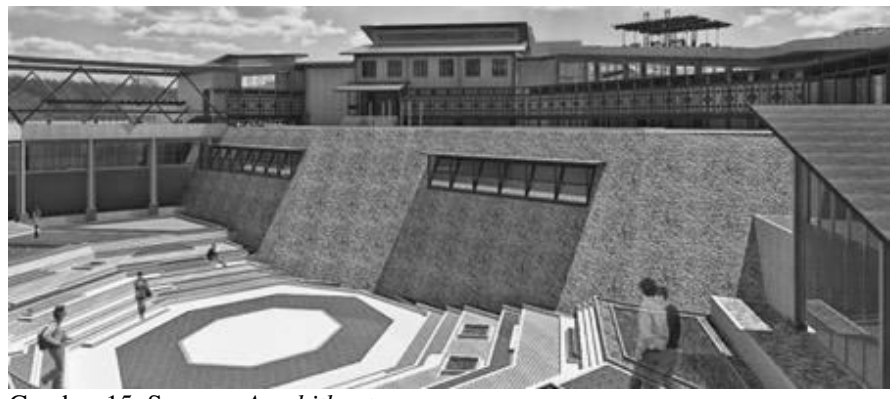

Gambar 15. Suasana Amphitheater

Sumber: Dokumentasi Pribadi

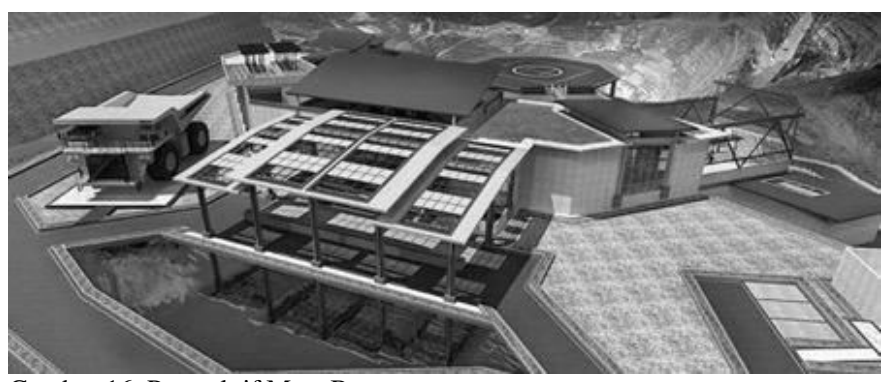

Gambar 16. Perspektif Mata Burung

Sumber: Dokumentasi Pribadi

\section{Peka Terhadap Iklim}

Pengaruh iklim pada bangunan harusnya sangat mempengaruhi bentuk keseluruhan bangunan. Dimana bangunan seharusnya bangunan ditepakan diantar lintasan matahari dan angin. Selain itu bentuk bangunan harus bisa melindungi dari matahari langsung dan air hujan.

Pada rancangan "Pusat Riset Pertambangan Grasberg", hemat energi dan peka terhadap iklim menjadi dasaran arsitektur ekologis yang paling banyak diterapkan. Pada desain ini dituntut untuk bisa mengurangi penggunaan energi serta bentukan bangunan yang menyusaikan dengan iklim dingin pada lingkungan site.

Selain itu Simbiosis dijadikan konsep utama dalam desain ini. Keterhubungan antara bangunan dengan lahan dijadikan perhatian utama. Dimana bangunan dibuat menyatu dengan lahan dan memiliki keterhubungan saling menguntungkan, bangunan dapat menjadikan lahan lebih produktif dan kembali hijau dengan fasilitas revegetasi sedangkan bangunan dapat memanfaatkan lingkungan sekitar untuk material bangunan dan membantu menjalankan sistem utilitas di dalam bangunan. 


\section{HASIL DAN EKSPLORASI}

\section{A. Eksplorasi Formal}

Transformasi bentuk lahan dihasilkan dari garisan kontur sehingga bentuk masa bangunan tetap terkesan menyatu dengan bentuk dasar bangunan, walaupun diberikan modifikasi bentuk geometri yang lebih formal.

Pembagian zoning juga dibuat berdasarkan dari level kontur yang sudah ada, sehingga tidak perlu melakukan cut and fill sehingga kembali pada pendekatan awal desain yaitu desain yang ekologis yang tidak menambah kerusakan lingkungan.

\section{B. Struktur}

Desain menggunakan rangka kolom dan balok baja. Dengan kolom baja profil king cross berukuran $60 \mathrm{~cm} \times 60 \mathrm{~cm}$ karena tipe model ini stabil untuk jenis bangunan yang tidak menggunakan pondasi tiang pancang. Sedangkan balok menggunakan baja profil I

\section{Penghawaan}

Pengaplikasian Double Skin Facade ini bertujuan agar udara di dalam ruangan akan berputar dengan baik namun tetap mendapat cahaya dari luar walaupun tidak secara langsung. Dengan adanya sistem ini pun energi yang dikeluarkan akan lebih sedikit.

\section{Desain Atap Green Roof}

Salah satu cara untuk melakukan penghijauan dan meningkatkan proses revegetasi dalam desain ini diaplikasikan green roof. Pada area ini diletakan panel - panel surya yang merupakan salah satu sumber energi listrik pada bangunan. Jenis tanaman yang pada green roof berupa perdu - perdu yang diambil dari sekitar site.

\section{E. Penampungan Air Hujan}

Salah satu penerapan pendekatan arsitektur ekologis yang hemat energi dalam desain ini adalah pemanfaatan ulang air hujan. Dalam desain ini sistem utilitas air bersumber utama dari kolam - kolam penampungan air hujan dan memanfaatkan gaya gravitasi untuk penyalurannya, sehingga dibuat beberapa penampungan serta pipa - pipa air yang mengikuti arah sirkulasi yang menurun ke arah kontur yang paling rendah.

\section{KESIMPULAN}

Objek arsitektur ini bertujuan untuk merehabilitasi lahan bekas tambang yang terbengkalai dengan pendekatan ekologis agar tetap menjaga keseimbangan alam dan membantu merehabilitasi lahan bekas tambang yang rusak ini. Selain itu dengan peneran konsep simbiosis yang diterapkan, adanya kegiatan pembangunan objek ini tidak akan terlalu merusak bentuk kontur pegunungan alami di sekitar lahan.

Melihat potensi dari lahan ini, sangat banyak yang bisa dipelajari dari sisa-sisa kegiatan penambangan. Olah karena ini mendirikan pusat riset untuk melakukan penelitian dan pelatihan mengenai pertambangan akan sangat tepat. Diharapkan dengan adanya objek ini dikedepannya akan bertambah fasilitas lain disekitar lahan yang juga nantinya dapat membantu merehabilitasi lahan bekas tambang serta membantu perkembangan perekonomian warga di sekitar lahan.

\section{DAFTAR PUSTAKA}

[1] A.Datar,P. Audet, D. Mulligan. 2011. Review - Post-Mined Land Rehabilitation in India: Cataloguing Plants Species Used in Land Revegetation. Centre for Mined Land Rehabilitation, Sustainable Minerals Institute, The University of Queensland. Brisbane.

[2] White, Edward T. 1983. Site analysis : diagramming information for architectural design. Tucson, Ariz. : Architectural Media

[3] Jormakka, K., Schürer, O., \& Kuhlmann, D. (2008). Design methods. Basel: Birkhäuser.

[4] Yeang, Ken. (2008). Ecodesign: A Manual for Ecological Design. Wiley Academy Zeisel, J. (1981). Inquiry by design: Tools for environmentbehavior research.

[5] Zeisel, J. (1981). Inquiry by design: Tools for environment-behavior research. Monterey, Calif: Brooks/Cole Pub. Co

[6] Neufert, Ernst, Data Arsitek Jilid 1 dan 2, Jakarta, penerbit erlangga, 2002

[7] Adler, David. (1999), Metric Handbook - Planning and Design Data, Architectural Press, UK

[8] De Chiara, Joseph; J Crosbie, Michael. 2001. Time Saver Standards for Residential Development. Singapore: Mc Graw Hill Book Companies Inc. 